\title{
Low Agricultural Potential Exacerbates the Effect of Temperature on Civil Conflicts
}

Jonathan Goyette ( $\sim$ jonathan.goyette@usherbrooke.ca )

University of sherbrooke https://orcid.org/0000-0002-7135-4709

Maroua Smaoui

University of Sherbrooke

Article

Keywords: agricultural potential, civil conflict, climate change

Posted Date: October 9th, 2020

DOI: https://doi.org/10.21203/rs.3.rs-78395/v1

License: (c) (i) This work is licensed under a Creative Commons Attribution 4.0 International License. Read Full License

Version of Record: A version of this preprint was published at Ecological Economics on February 1st, 2022. See the published version at https://doi.org/10.1016/j.ecolecon.2021.107250. 


\title{
Low agricultural potential exacerbates the effect of temperature on civil conflicts
}

June 23, 2020

\begin{abstract}
A large body of literature, spanning many social sciences, examines the effect of climate change on organized violence and various mechanisms could explain how climate shocks instigate and perpetuate conflict (1). One strand of literature argues that climate shocks exacerbate the competition over resources $(2),(3),(4),(5)$. In this paper, we examine the impact of rising temperatures on the incidence of civil armed conflicts, focusing on a specific link: the basic agricultural potential of a country free from human interventions. Using data for 172 countries from 1946 until 2014, we conduct a natural experiment and identify the effect of the interaction between time-wise variations in temperature within a country and the cross-country variation in agricultural potential on conflict incidence. We find that there is a significantly higher probability (4\%) to be in conflict when annual temperature deviates from its mean in a country with low agricultural potential relative to a country with high agricultural potential. An analysis of the long-term relationship (decennial averages) points to a mitigation of the negative impact of the interaction on civil conflicts, especially for countries with high agricultural potential. The findings also suggest that the interaction has no significant effect in countries with exportable resources such as oil. This is the first study to show that initial agricultural conditions play a significant role to understand the climate-conflict linkages on a global scale.
\end{abstract}


Introduction Climate change will have many adverse consequences on human kind, one of which is potential increases in interpersonal and intergroup violence (6). There is however an ongoing debate about the importance of a direct effect of climate change on violence (7),(8) and scientists now tend to refer to climate change as a multiplier of threats rather than a primary driver of conflict. An array of complex interactions between climate change and other factors is thus likely at play in the climate-violence linkage. Four drivers of conflict seem particularly influential: 1) low socio-economic development, 2) low capabilities of the state, 3) intergroup inequality and 4) a recent history of violence, while geography rates very low as a potential driver of conflict (9). There is however a long tradition of scholarly thinkers who argue that climate and geography have shaped human societies (10), (11) and that some of the aforementioned drivers of conflicts are potentially correlated to climate and geography through a historical process (12). Analysis of archeological data on the collapse of various civilizations shows that rather than being the cause of the disintegration, violent conflicts commonly resulted from natural resource degradation (13) or from the non-linear impact of a climate event (14),(15). Similar dynamics are at play in contemporary conflicts, occurring over land, water, forest, etc. (16) and climate events might exacerbate the competition over these resources. Thus, disentangling the effects of the drivers of conflict which result from a historical process from the effect of the initial geographical conditions of a country might inform us on specific mechanisms linking climate to violence. This study aims at establishing the causal link between temperature and conflicts through the magnifying effects of agricultural potential, using a natural experiment approach.

Methodology and data In order to assess the importance of agricultural potential in the climate-conflict linkage, we build a linear probability model to examine the effect of the interaction between temperature and agricultural potential on conflict incidence. There are at least two issues which complicate the statistical analysis of the climate-conflict linkage: 1) drivers of conflict may interact in a feedback loop with conflict, and 2) we might observe a correlation between conflict and a potential driver because both variables are related to a third unobserved variable. Two features of the model we use reduce concerns about these issues and heighten the power of the model to identify a causal link which is statistically significant. First, the interaction between climate fluctuations and geographic characteristics can safely be assumed to be free from human intervention, i.e., conflict cannot interact in a feedback loop with the interaction variable (17), (18). Second, the model uses country fixed effects to control for characteristics in a country which do not vary, or vary slowly, over time (e.g. geography, institutions, etc.) as well as year fixed effects to control for specific events which might affect a subgroup of countries at the same time. These fixed effects take care of the issue of unobserved variables. Our approach is akin to a natural experiment. Countries exhibiting high agricultural potential act as a control 
group for countries with a lower agricultural potential and the annual variation in temperature act as a treatment from one period to the next. This allows identifying the causal effect of the interaction on the incidence of conflict.

The conflict data comes from the Uppsala Conflict Data Program (19),(20), which defines a conflict based on 25 or more battle-related deaths. However, given climatic events are potentially associated with various types of conflicts: riots, unilateral violence, civil or interstate wars, etc., we focus on conflicts with a clearly defined political incompatibility. Moreover, due to the decrease in interstate conflicts and the recrudescence of civil conflicts since the end of the cold war, we focus on intrastate conflicts which involve the government and at least one other organized party. We use a binary variable to describe conflict incidence which takes value one if there is a conflict in a country in a specific year and zero otherwise (see Figure 1).

Data on climate variables comes from the Climatic Research Unit of the University of East Anglia (21). We focus on temperature variations (see Figure 1), as it has been shown that other climate variables have an impact on conflicts mainly through changes in temperature (22).

We define agricultural potential based on the project for Global Agricultural Productivity and Ecological Zones (GAEZ) from the Food and Agricultural Organization (23). GAEZ classifies land area into eight categories using a suitability index (SI). This SI is built by evaluating the potential to grow 280 types of cereals based on intrinsic geographical and soil characteristics of a country which change very slowly over time. We further define agricultural potential based on cereals potential yields from a rain regime and a low level of inputs, i.e., an agricultural potential with no human intervention in terms of irrigation, mechanization, chemicals and/or nutrients. We can thus compare the basic potential to grow cereals across countries abstracting from human interventions and avoid the feedback loop going from conflict to agricultural yields. More particularly, agricultural potential of a country is define as the ratio of its land area with an SI above a certain threshold over its total land area. In this paper, we present the results using an SI above a medium threshold (see Figure 1), but the choice of threshold has no impact on the qualitative nature of the results.

Results We find that countries with low agricultural potential have a larger probability than high agricultural potential countries to be in conflict in response to a deviation from their mean annual temperature (see column 2 Figure 2). The total effect of temperature on conflict incidence is the sum of the coefficients on temperature and the coefficient of the interaction term multiplied by the level of agricultural potential of the country under examination (see model in supplementary material). For example, if we set agricultural potential to zero (eg. a country with no land above the medium SI threshold), a change of one degree Celsius is associated with an increase in the probability of being in conflict by $4.1 \%$ relatively to better endowed countries. 
Instead, if agricultural potential is set to one (eg. a country with all of its surface above the medium threshold), the effect of a change of one degree Celsius on the probability of being in conflict is approximately $-5.1 \%$ relative to poorly endowed countries.

In columns 3 and 4 on Figure 2, we examine other aspects of the climate-conflict relationships. Given climate variables often present anomalies, it is customary to normalize such variables (24). We use the standardized distribution of temperature with mean zero and a variance of one and find the correlation persists (see column 3 on Figure 2).

Annual averages might be symptomatic of weather shocks but not representative of the distribution of these shocks over the long-run (1). We thus examine decade averages which are more representative of climate change (see column 4 on Figure 2). We observe a very small decline of the effect of temperature on conflict over the long-run with the probability of being in conflict decreasing from $4.1 \%$ to $3.9 \%$ in countries with low agricultural potential relative to well-endowed countries. However, the mitigating effect of a high agricultural potential is much stronger in the long run than in the short run. The probability of being in conflict decreases from $-5 \%$ to $-10 \%$ in response to a one degree Celsius deviation from the decennial mean in a country with high agricultural potential relative to low potential countries.

Figure 3 presents a graphical depiction of the relation between the interaction and predicted conflict incidence (see supplementary material). The two red areas depict the highest levels of predicted conflict incidence for given temperature and SI intervals. Take two countries with a similar average temperature, say between 21 and 22 Celsius, which corresponds to Iraq and Swaziland in our sample. Iraq has only $5 \%$ of its surface with an SI above the medium threshold whereas $33 \%$ of Swaziland surface is above the SI medium threshold. From Figure 3, predicted incidence of conflict for Iraq (0.21) is about 1.5 times that for Swaziland (0.14) and actual conflict incidence data indicate that Iraq has been in conflict $68 \%$ of the time during the 1946-2014 period, while Swaziland has not been in conflict since its independence (1968).

Other drivers In table 1, we examine three potential drivers which might compete with agricultural potential to exacerbate the effect of temperature on conflict. First, we compare countries based on their agricultural share of GDP. In column 1 Table 1, we use a $10 \%$ agricultural share of GDP to compare non-agricultural and agricultural countries (we have tested other thresholds and it does not affect the results). The coefficient for the interaction is significant and similar in magnitude for both type of countries. Agricultural potential is relevant for both type of countries but it operates through different channels. In agricultural countries, the impact of the interaction might be direct, e.g., food security, while in non-agricultural countries the impact might be indirectly link to conflict through the historical process of institutional and state capacity development(25). The results in column 2 Table 1 tend to corroborate this interpretation. We 
examine the impact of socio-economic development and state-capacity by parting countries based on their OECD membership. The coefficients on the interaction term are similar in magnitude and statistical significance for both type of countries. Finally, we compare countries based on their OPEC membership. In column 3 Table 1, the coefficient of the interaction for OPEC countries is not significant, implying that the causes of conflict in these countries has probably more to do with a competition over exportable resources such as oil rather than low agricultural potential.

Robustness We check whether the association between conflict incidence and the interaction is robust to various specifications and statistical models used in previous studies (see supplementary material for the methodologies and statistical results behind the assertions presented in this paragraph). Using a nonlinear probability model does not affect the qualitative nature of the results. As an alternate measure of agricultural potential, we use the intrinsic hydrological characteristics of a country which do not vary (or very little) across time as opposed to water resources which could be affected by sudden variations in temperature. Using the level of water scarcity across major water basins from GAEZ, we continue to find a significant influence of initial geographical conditions on conflict. Finally, we control for some socio-economic covariates (contemporary or lagged) which are potentially related to conflict: log GDP per capita, inflation, population growth, openness to trade and education and our main result persists. One final concern is about the use of long time series and non-stationarity. We show that temperature and conflict taken in levels do not exhibit non-stationary processes.

Discussion We find that the interaction between variations in temperature and variations in agricultural potential is associated with the incidence of conflict in agricultural and nonagricultural economies. Identifying the initial conditions which contribute to the climate-conflict relationship is a step toward a better understanding of the mechanisms underlying current conflicts, namely through the historical process linking agricultural potential to the four main current drivers of conflict as well as through the direct effect of agricultural potential on current food security. Moreover, our findings suggest that the impact of the interaction is non-linear (18). Unfavorable agricultural potential may lead to a history of violence through poor self-reinforcing socio-economic outcomes (12) while favorable agricultural potential may allow for the development of a bureaucracy which can sustain better institutions (25). In turn, these better institutions may prove more resilient to the adverse consequences of a climatic event which could otherwise lead to a civil conflict, such as a negative shock on income (26) or increasing food or cattle prices (27),(28). Environmental stress impacts humans at the individual level (29),(30) and at the macro-level (2). Climate shocks interacted with agricultural potential might also generate violence beyond a country's border through population displacement (31) and through contagion 
(32),(33) as neighboring countries share similar climatic and geographical characteristics.

Conclusion The research agenda should focus on specific transmission channels linking a country's initial and current geographical conditions to conflict in order to identify the potential drivers of armed violence. Understanding these various climate-conflict linkages is crucial to develop a global damage function of climate change and assess the costs of various local and global scenarios from laissez-faire to mitigation and/or adaptation (34). Since it is safe to assume that initial agricultural conditions evolve very slowly over time, such a global damage function, which integrates climate-geography-conflict linkages, may be useful to predict and avoid armed conflicts. Based on our findings, international aid could target countries with low agricultural potential and weak institutions. Transfers to these recipient countries could occur in times where temperature variations significantly increase the risk of conflict. International mechanisms to reduce price fluctuations for basic staples and cereals could also potentially reduce conflict incidence in countries with low agricultural potential.

\section{References}

[1] Dell, M., Jones, B. F. \& Olken, B. A. What do we learn from the weather? the new climate-economy literature. Journal of Economic Literature 52, 740-98 (2014).

[2] Collier, P. \& Hoeffler, A. On the incidence of civil war in africa. Journal of conflict resolution 46, 13-28 (2002).

[3] Humphreys, M. Economics and violent buconflict. Cambridge, MA (2003).

[4] Glaeser, E. L. The political economy of hatred. The Quarterly Journal of Economics 120, 45-86 (2005).

[5] Berman, N., Couttenier, M., Rohner, D. \& Thoenig, M. This mine is mine! how minerals fuel conflicts in africa. American Economic Review 107, 1564-1610 (2017).

[6] Hsiang, S. M. \& Burke, M. Climate, conflict, and social stability: what does the evidence say? Climatic Change 123, 39-55 (2014).

[7] Buhaug, H. Climate not to blame for african civil wars. Proceedings of the National Academy of Sciences 107, 16477-16482 (2010).

[8] Hsiang, S. M., Burke, M. \& Miguel, E. Reconciling climate-conflict meta-analyses: reply to buhaug et al. Climatic change 127, 399-405 (2014). 
[9] Mach, K. J. et al. Climate as a risk factor for armed conflict. Nature 1 (2019).

[10] Hippocrate, d. C. Traits airs, des eaux et des lieux (Antiquit

[11] Montesquieu, C. d. S. b. d. L'Esprit des lois (Barrillot et fils, 1748).

[12] Iyigun, N. N., Murat \& Qian, N. The long-run effects of climate change on conflict, 14001900. Working Paper Harvard University 66 (2019).

[13] Brander, J. A. \& Taylor, M. S. The simple economics of easter island: A ricardo-malthus model of renewable resource use. American economic review 119-138 (1998).

[14] Gibbons, A. How the akkadian empire was hung out to dry. Science 261, 985-986 (1993).

[15] Kuil, L. et al. Learning from the ancient maya: Exploring the impact of drought on population dynamics. Ecological Economics 157, 1-16 (2019).

[16] Homer-Dixon, T. F. Environmental scarcities and violent conflict: evidence from cases. International security 19, 5-40 (1994).

[17] Dell, M., Jones, B. F. \& Olken, B. A. Temperature shocks and economic growth: Evidence from the last half century. American Economic Journal: Macroeconomics 4, 66-95 (2012).

[18] Burke, M., Hsiang, S. M. \& Miguel, E. Climate and conflict. Annu. Rev. Econ. 7, 577-617 (2015).

[19] Gleditsch, N. P., Wallensteen, P., Eriksson, M., Sollenberg, M. \& Strand, H. Armed conflict 1946-2001: A new dataset. Journal of peace research 39, 615-637 (2002).

[20] Pettersson, T. \& Wallensteen, P. Armed conflicts, 1946-2014. Journal of Peace Research 52, 536-550 (2015).

[21] Harris, I., Jones, P., Osborna, T. \& Listera, D. Updated high-resolution grids of monthly climatic observations-the cru ts3. 10 dataset (2013).

[22] Burke, M. B., Miguel, E., Satyanath, S., Dykema, J. A. \& Lobell, D. B. Warming increases the risk of civil war in africa. Proceedings of the national Academy of sciences 106, 2067020674 (2009).

[23] FAO. Quést-ce que gaez? http://www.fao.org/nr/gaez/faqs/fr/ (2018).

[24] Barrios, S., Bertinelli, L. \& Strobl, E. Trends in rainfall and economic growth in africa: A neglected cause of the african growth tragedy. The Review of Economics and Statistics $\mathbf{9 2}$, 350-366 (2010). 
[25] Diamond, J. Guns, germs, and steel: the fates of human societies. NY: WW Norton $\&$ Company 14 (1997).

[26] Miguel, E., Satyanath, S. \& Sergenti, E. Economic shocks and civil conflict: An instrumental variables approach. Journal of political Economy 112, 725-753 (2004).

[27] Rosenzweig, C., Parry, M. L. et al. Potential impact of climate change on world food supply. Nature 367, 133-138 (1994).

[28] Maystadt, J.-F. \& Ecker, O. Extreme weather and civil war: does drought fuel conflict in somalia through livestock price shocks? American Journal of Agricultural Economics 96, 1157-1182 (2014).

[29] Tiihonen, J., Räsänen, P. \& Hakko, H. Seasonal variation in the occurrence of homicide in finland. American Journal of psychiatry 154, 1711-1714 (1997).

[30] Anderson, C. A. Temperature and aggression: Ubiquitous effects of heat on occurrence of human violence. Psychological bulletin 106, 74 (1989).

[31] McLeman, R. International migration and climate adaptation in an era of hardening borders. Nature Climate Change 9, 911-918 (2019).

[32] Buhaug, H. \& Gleditsch, K. S. Contagion or confusion? why conflicts cluster in space. International Studies Quarterly 52, 215-233 (2008).

[33] Sandholt, K. S., J. P. Gleditsch. Rain, growth, and civil war: the importance of location. Defence Peace Econ 20, 359372 (2009).

[34] Burke, M., Davis, W. M. \& Diffenbaugh, N. S. Large potential reduction in economic damages under un mitigation targets. Nature 557, 549 (2018).

Ackowledgements: Jonathan Goyette was supported by the Fonds de recherche québecois en sciences et cultures. The authors wish to thank seminar participants at Waseda University, IDE-JETRO, Sophia University, Université de Bordeaux et Université de Montpellier. This paper initially circulated with the following title: "Civil armed conflict: the interaction between climate change and agricultural potential"

Competing Interests: The authors declare that they have no competing financial interests. Correspondence and requests for materials should be addressed to jonathan.goyette@usherbrooke.ca 
Figure 1: Distributions of temperature, conflict incidence and suitability index, 1946-2014
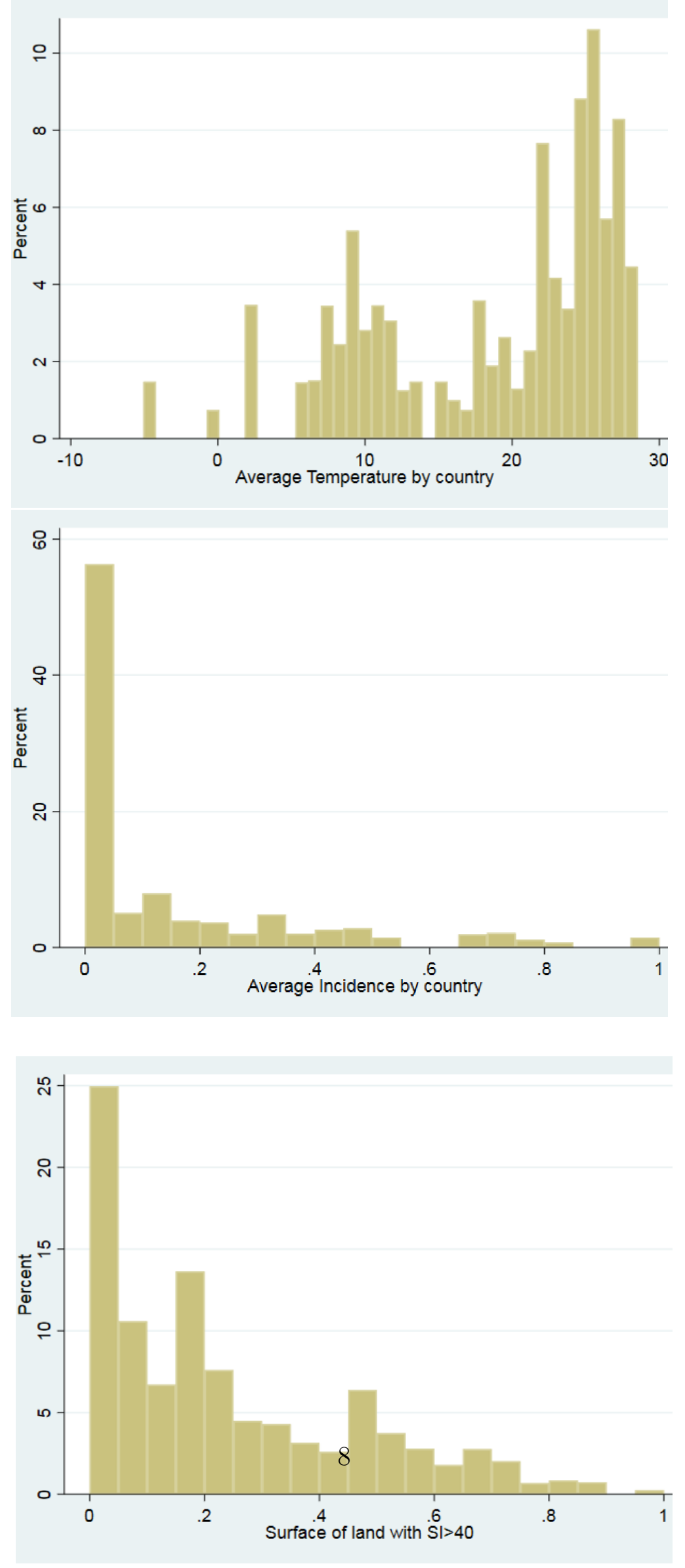
Figure 2: Linear probability model: main estimates

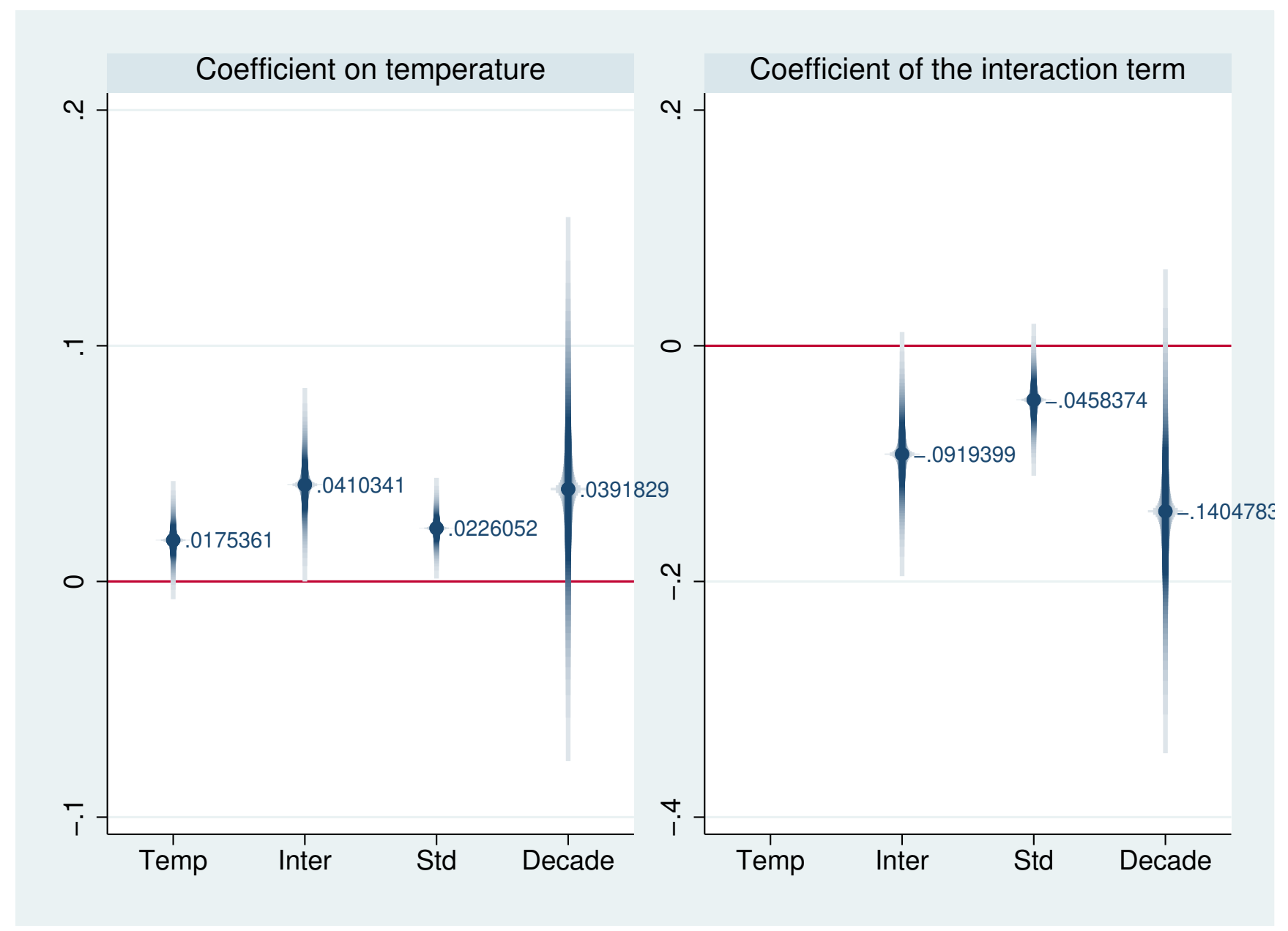

Note: Robust std. err. are clustered at country level to build the confidence intervals; 9344 observations except for Decade (990 obs.); all regressions include a constant, time and country fixed effects; Temp: only additional covariate is temperature; Inter: additional covariates are Temperature and Interaction; Std: using standardized temperature with mean 0 and variance 1; Decade: using decennial temperature averages. Let us recall that agricultural potential does not vary over time and is thus captured by the country fixed effects in all regressions. 
Figure 3: Predicted conflict incidence against Average Temperature and Agricultural potential

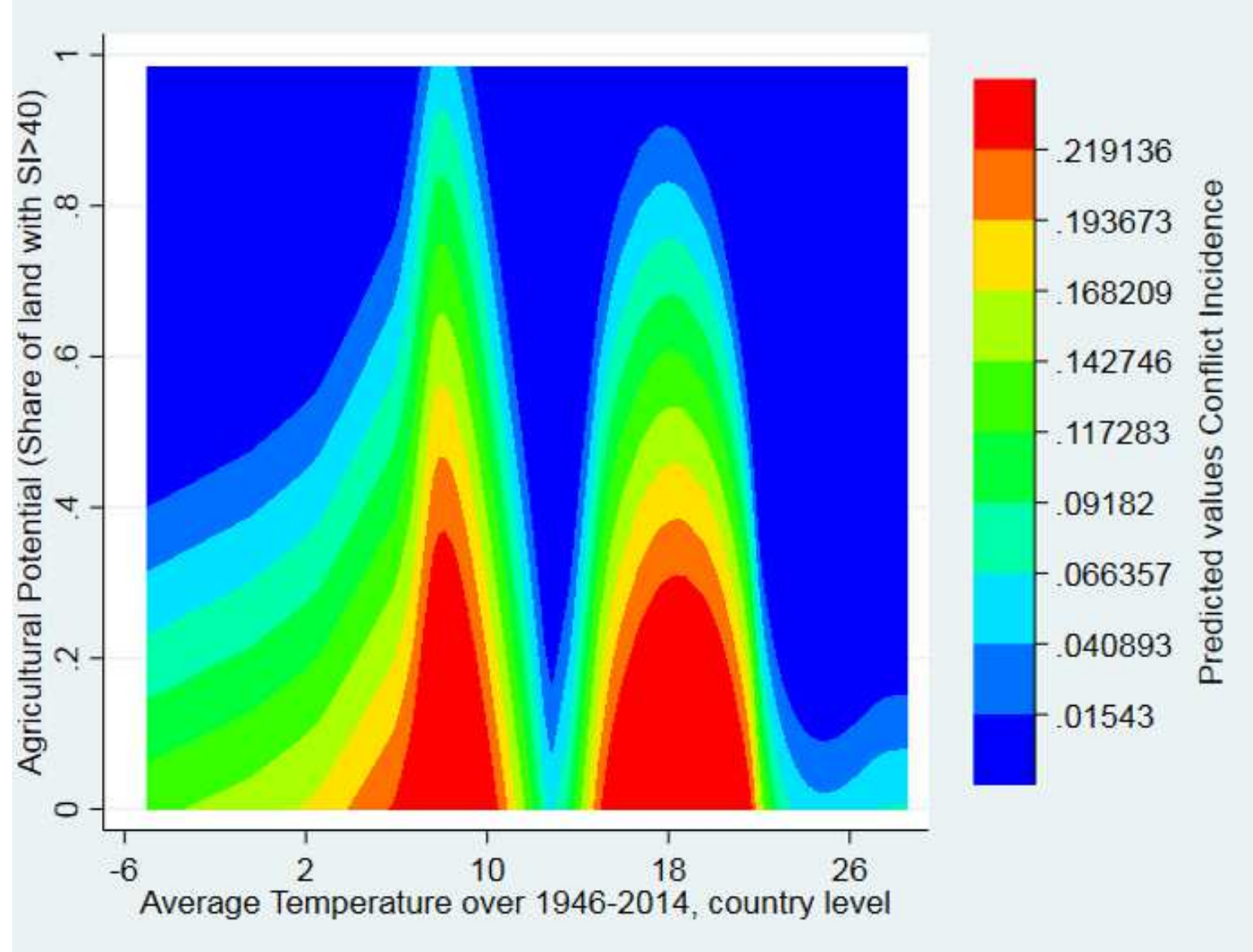


Table 1: Subgroups estimates

\begin{tabular}{|c|c|c|c|}
\hline & (1) & (2) & (3) \\
\hline Temperature & $\begin{array}{l}0.040^{*} \\
(2.02)\end{array}$ & $\begin{array}{c}0.041^{* *} \\
(2.56)\end{array}$ & $\begin{array}{c}0.040^{* *} \\
(2.56)\end{array}$ \\
\hline Interaction agricultural & $\begin{array}{c}-0.113^{* *} \\
(-2.12)\end{array}$ & & \\
\hline Interaction non-agricultural & $\begin{array}{c}-0.111^{* *} \\
(-2.08)\end{array}$ & & \\
\hline Interaction OECD & & $\begin{array}{c}-0.092^{*} \\
(-1.84)\end{array}$ & \\
\hline Interaction non-OECD & & $\begin{array}{c}-0.092^{*} \\
(-1.96)\end{array}$ & \\
\hline Interaction OPEC & & & $\begin{array}{l}0.213 \\
(0.82)\end{array}$ \\
\hline Interaction non-OPEC & & & $\begin{array}{c}-0.092^{* *} \\
(-2.33)\end{array}$ \\
\hline adj. $R^{2}$ & 0.035 & 0.040 & 0.040 \\
\hline$N$ & 5532 & 9344 & 9344 \\
\hline $\begin{array}{l}t \text {-statistics in parentheses; Robust } \\
\text { All regressions include a constant, } \\
{ }^{*} p<0.1,{ }^{* *} p<0.05,{ }^{* * *} p<0.01\end{array}$ & $\begin{array}{l}\text { std. err. c } \\
\text { year and c }\end{array}$ & $\begin{array}{l}\text { astered at } \\
\text { untry fixec }\end{array}$ & $\begin{array}{l}\text { untry level. } \\
\text { effects. }\end{array}$ \\
\hline
\end{tabular}


Figures
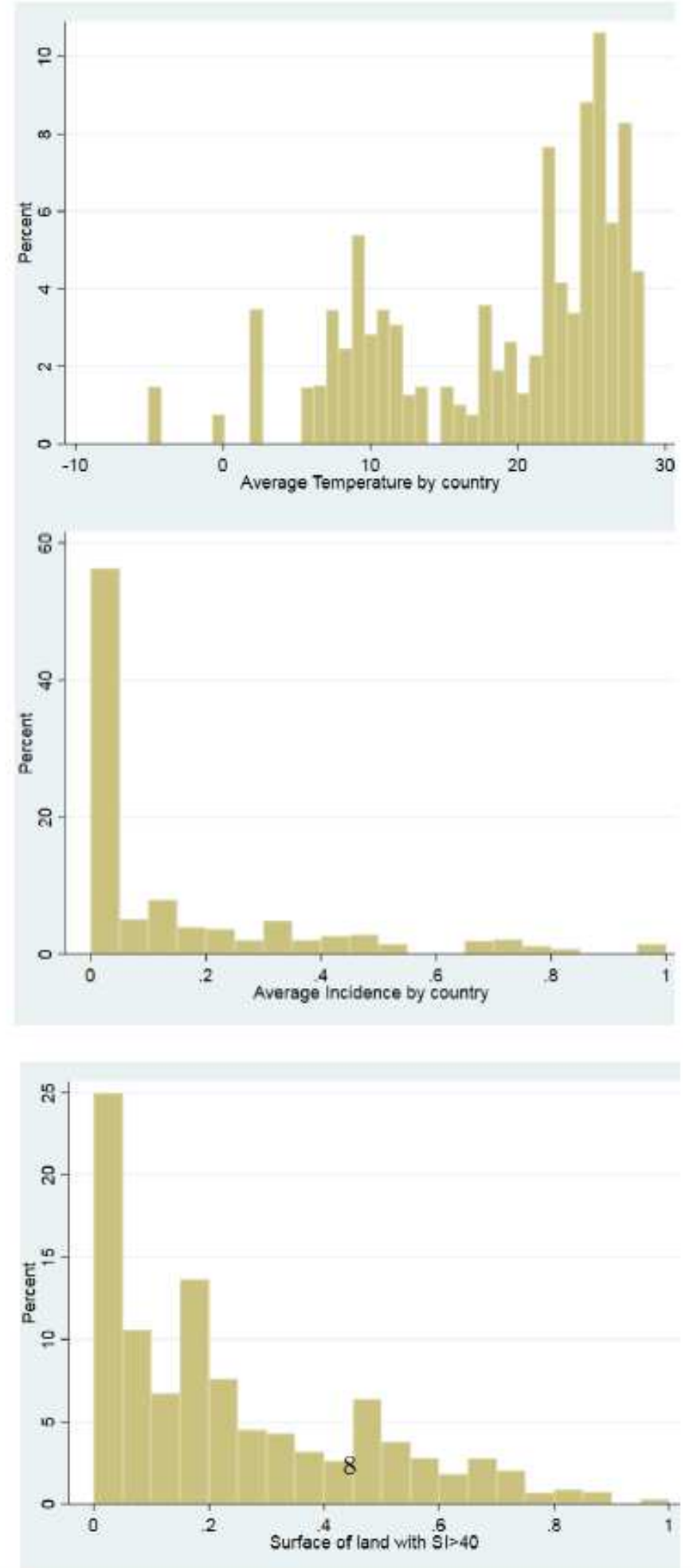

Figure 1

Distributions of temperature, conflict incidence and suitability index, 1946-2014 


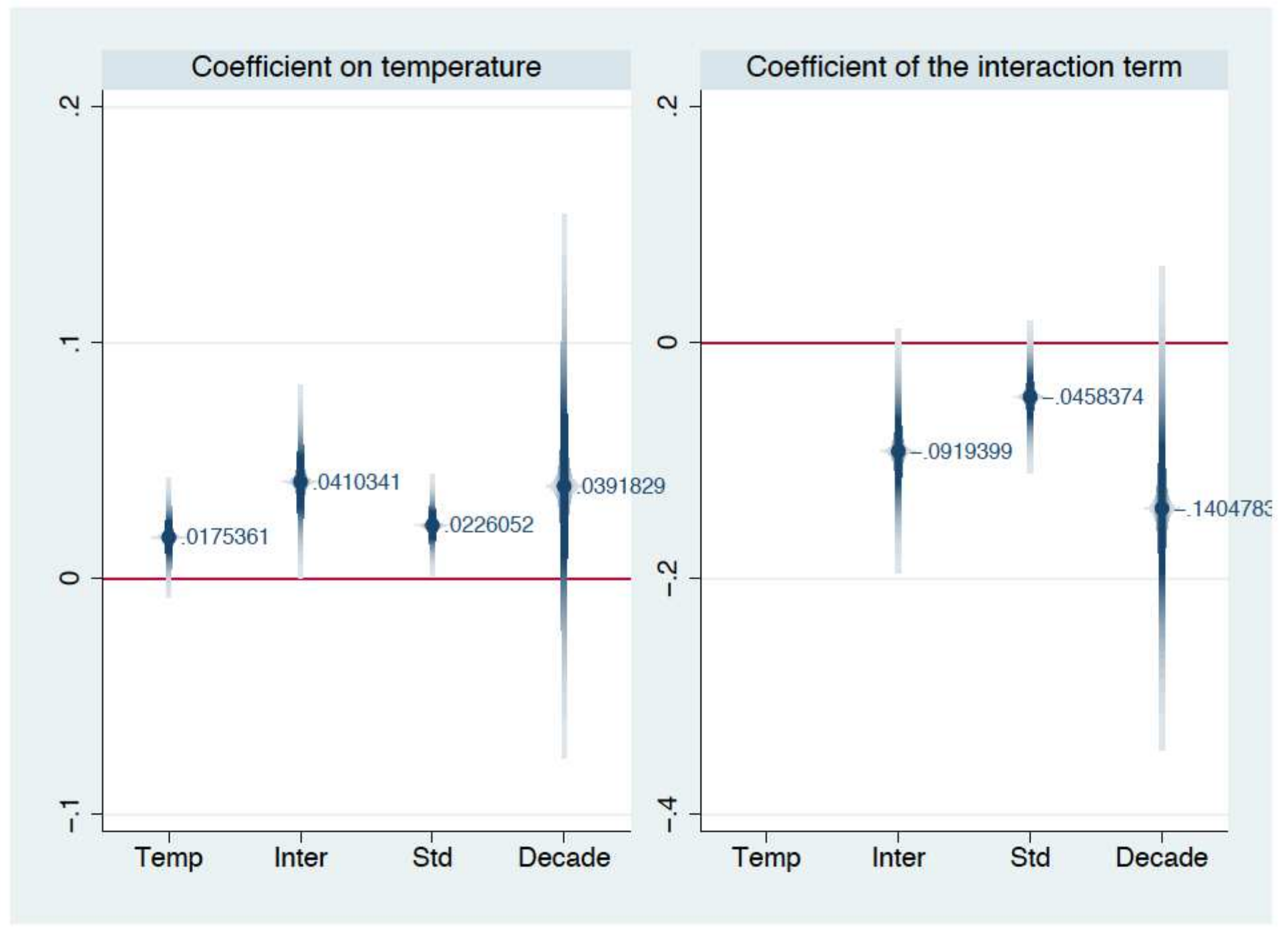

Figure 2

Linear probability model: main estimates. Note: Robust std. err. are clustered at country level to build the confidence intervals; 9344 observations except for Decade (990 obs.); all regressions include a constant, time and country fixed effects; Temp: only additional covariate is temperature; Inter: additional covariates are Temperature and Interaction; Std: using standardized temperature with mean 0 and variance 1; Decade: using decennial temperature averages. Let us recall that agricultural potential does not vary over time and is thus captured by the country fixed effects in all regressions. 


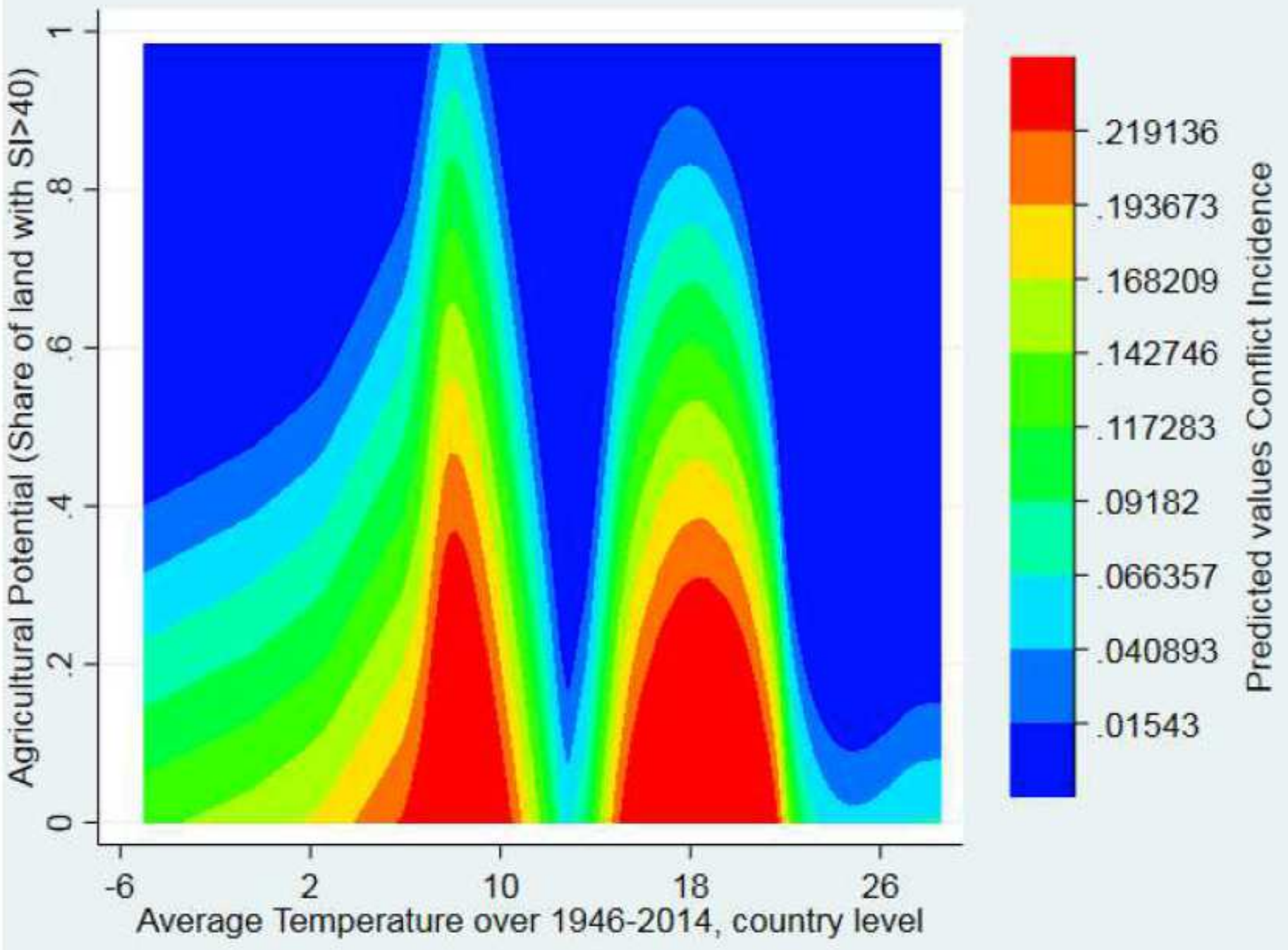

Figure 3

Predicted conflict incidence against Average Temperature and Agricultural potential

\section{Supplementary Files}

This is a list of supplementary files associated with this preprint. Click to download.

- SupplementaryMaterialanonym.pdf 